\title{
Desenvolvimento, Caracterização e Aceitação de Brownie de Biomassa de Fruta-Pão Verde
}

\section{Development, Characterization and Acceptance of Brownie of Green Breadfruit Biomass}

\author{
Iris Lengruber Gonçalves Teixeira de Almeida ${ }^{a *}$; Marcia Barreto da Silva Feijóa ; Paulo Sergio Marcelliniab
}

\author{
aUniversidade Federal do Estado do Rio de Janeiro, Programa de Pós-Graduação Stricto Sensu em Alimentos e Nutrição, RJ, Brasil \\ bUniversidade Federal do Estado do Rio de Janeiro, Programa de Pós-Graduação Stricto Sensu em Enfermagem e Biociências, RJ, Brasil \\ *E-mail: irislengruber@hotmail.com
}

Recebido: 28 de maio de 2015; Aceito: 17 de novembro de 2015

\begin{abstract}
Resumo
O presente estudo objetivou desenvolver e caracterizar um brownie de biomassa de fruta-pão verde. Foi desenvolvido um brownie formulado com biomassa de fruta-pão verde em detrimento dos ingredientes tradicionais: farinha de trigo e manteiga. Foi analisado em quintuplicata quanto à composição centesimal (umidade por voláteis a $105^{\circ} \mathrm{C}$; cinzas por calcinação; extrato etéreo pelo método de Soxhlet; proteína pelo método semi-micro Kjeldahl; amido pelo método de Lane-Eynon) conforme metodologias recomendadas pelo Instituto Adolfo Lutz, exceto a fibra, que foi quantificada pelo método proposto por Van Söest. Foi determinada ainda a capacidade antioxidante (DPPH), e o teor de compostos fenólicos totais (Folin-Ciocalteu). O brownie desenvolvido foi submetido a análise sensorial com 100 provadores não treinados e o resultado foi comparado com uma versão tradicional e com outras duas marcas comerciais de brownie sem glúten e sem lactose. Na composição centesimal, a fibra representa uma importante fração no brownie desenvolvido $(12,07 \pm 0,29)$. Quanto à capacidade antioxidante, o brownie apresentou excelente resultado (DPPH - 85\% e 654,76 $\pm 4,10 \mathrm{mg} / 100 \mathrm{~g}$ de ácido gálico equivalente), superior a algumas frutas. O produto desenvolvido foi bem aceito sensorialmente, apresentando índice de aceitação superior a 70\% na avaliação global. Concluiu-se, que há viabilidade na produção de brownie de biomassa de fruta-pão verde, uma vez que se mostrou com apelo nutritivo ainda maior que outros com os quais foi comparado e foi bem aceito sensorialmente. Poderia ser interessante um estudo de otimização da formulação para melhorar a textura do brownie.
\end{abstract}

Palavras-chave: Artocarpus. Antioxidantes. Alimento Funcional.

\section{Abstract}

This study aimed to develop and characterize a brownie of green breadfruit biomass. We developed a brownie made with green breadfruit biomass to the detriment of traditional ingredients: flour and butter. It was analyzed in five replications on the centesimal composition (moisture volatile at $105{ }^{\circ} \mathrm{C}$; ashes by calcination; ether extract Soxhlet; protein by the semi-micro Kjeldahl method; starch by Lane-Eynon method) as methodologies recommended by the Adolfo Lutz Institute [1], except the fiber, which was quantified by the method proposed by Van Söest [2]. It was further determined the antioxidant capacity (DPPH) and the content of total phenolic compounds (Folin-Ciocalteu reagent). The brownie developed was subjected to sensory analysis 100 untrained tasters and the result was compared to a traditional version and two trademarks of brownie with no gluten and lactose. On the centesimal composition, the fiber is an important fraction in developed brownie (12.07 \pm 0.29$)$. For antioxidant capacity, the brownie showed excellent results (DPPH - 85\% and $654.76 \pm 4.10 \mathrm{mg} / 100 \mathrm{~g}$ of equivalent gallic acid) greater than some fruits. The product developed was sensory well accepted, with higher acceptance rate than $70 \%$ in the overall assessment. It was concluded that there is viability in the production of brownie of green breadfruit biomass, since proved it has nutritional appeal even higher than others, with which it was compared, and it was sensorially well accepted. One formulation optimization study might be interesting to improve the brownie texture.

Keywords: Artocarpus. Antioxidants. Functional Food.

\section{Introdução}

Entre os vários alimentos considerados funcionais encontram-se as frutas, e grande destaque deve ser dado às frutas tropicais cultivadas no Brasil, que apresenta condições extremamente favoráveis quanto à adaptação dessas espécies. Com isso, o consumo de frutas tropicais tem aumentado ano após ano devido ao valor nutritivo e a seus efeitos terapêuticos, apesar de existir uma grande diversidade de frutas e produtos derivados ainda pouco pesquisados com relação as suas propriedades e capacidades benéficas à saúde, bem como suas variáveis de utilização.
Nutricionalmente, a fruta-pão é rica em carboidratos e uma boa fonte de fibra dietética, de cálcio, cobre, ferro, magnésio, potássio, tiamina, além de ser boa fonte de antioxidantes. No entanto, ainda é uma fruta subutilizada em nosso país.

Em tempos de valorização de temas como alimento funcional, aproveitamento integral dos alimentos, utilização de resíduos, e diversas alternativas com apelo nutritivo e de baixo custo para alimentação da população, torna-se contraditório tanto desperdício da fruta-pão nos quintais brasileiros.

Por toda sua riqueza nutricional e funcional, e também pelo baixo custo e facilidade de acesso a essa fruta, 
objetivou-se desenvolver produtos utilizando-a como matéria-prima. Nesse contexto, considerou-se interessante o desenvolvimento de uma biomassa de fruta-pão verde, que foi utilizada na formulação de um brownie, substituindo ingredientes tradicionalmente utilizados, como a manteiga e a farinha de trigo, atendendo assim ao apelo dos intolerantes à lactose e doentes celíacos, a um preço bem mais acessível que os atualmente oferecidos no mercado, tendo ainda o apelo funcional por ter se mostrado rico em fibras e antioxidantes.

\section{Material e Métodos}

O brownie foi produzido com uma receita original ${ }^{1}$, na qual foi feita a substituição dos ingredientes manteiga e farinha de trigo por biomassa de futa-pão verde. O brownie foi assado em forno pré-aquecido a $180{ }^{\circ} \mathrm{C}$ por 15 minutos em forma de alumínio sem untar. Após assados, os brownies foram esfarelados manualmente e uma parte foi retirada para análise de umidade e o restante foi espalhado em um tabuleiro de alumínio de forma homogênea e levado à estufa a $105{ }^{\circ} \mathrm{C}$ para desidratar. Após desidratado, foi triturado em liquidificador doméstico até que se tornasse um pó homogêneo e posteriormente armazenado em vidro com tampa.

\subsection{Composição centesimal}

As análises foram feitas em quintuplicata e os procedimentos metodológicos foram realizados no Laboratório de Bromatologia da Universidade Federal Fluminense.

A umidade foi determinada por gravimetria, em estufa a $105{ }^{\circ} \mathrm{C}$ até peso constante, de acordo com o método recomendado pelo Instituto Adolfo $\mathrm{Lutz}^{2}$, assim como o resíduo mineral fixo, em mufla a $550{ }^{\circ} \mathrm{C}$ até peso constante.

A fração extrato etéreo foi determinada em extrator intermitente de Soxhlet, utilizando-se Éter Etílico P. A. como solvente ${ }^{2}$.

A proteína foi determinada pelo método de Kjeldahl (semi-micro), o qual se baseia na destruição da matéria orgânica seguida de destilação, sendo o nitrogênio dosado por volumetria. O fator 6,25 foi utilizado para converter o teor de nitrogênio total em proteína de acordo com os fatores de conversão usados pela $\mathrm{FAO} / 73^{2}$.

O carboidrato foi determinado em amido, pelo método de Lane-Eynon, que se baseia na capacidade dos glícides, em meio fortemente alcalino e a quente, de formar enodiol, composto com forte poder redutor, que em presença de $\mathrm{Cu}++$, se oxida e reduz o cobre a $\mathrm{Cu}+$, dando origem a um precipitado vermelho tijolo de $\mathrm{Cu}_{2} \mathrm{O}^{2}$.

A fibra foi determinada pelo método proposto por Van Söest ${ }^{3}$, que utiliza uma solução detergente neutra (NDF) que solubiliza todo material vegetal, excetuando-se a estrutura da parede, que são as fibras insolúveis (celulose, hemiceluloses e lignina). Depois o resíduo de NDF é filtrado a vácuo, e posteriormente é lavado com água destilada fervente, seguida da lavagem com Acetona P.A. para melhor secagem.
Este método quantifica a fração insolúvel da fibra (celulose, hemiceluloses e lignina).

\subsection{Capacidade antioxidante}

Os extratos foram analisados em triplicata, no Laboratório de Bioativos da Universidade Federal do Estado do Rio de Janeiro (Unirio).

Para os extratos, foram pesados 10 gramas da amostra dessecada em um tubo e acrescentados $10 \mathrm{ml}$ de água (para extrato aquoso) e em outro tubo com $10 \mathrm{ml}$ de etanol (para o extrato alcoólico). Após uma hora os tubos foram centrifugados por 10 minutos a 20.000 rotações por minuto com aceleração de 20 segundos e desaceleração de 30 segundos $^{4}$.

Cada solução de amostra foi submetida à determinação da capacidade de sequestrar o radical 1,1-difenil-2-picrilhidrazil (DPPH), segundo método descrito por Brand-Williams et al. (1995), modificado por Miliauskas et al. (2004), e referenciado por Prior; Wu e Schaich ${ }^{4}$. A medida de absorbância do radical após uma hora de reação foi realizada no comprimento de $517 \mathrm{~nm}$. A queda na leitura da densidade ótica das amostras foi correlacionada com o controle, estabelecendo-se a porcentagem de descoloração do radical DPPH, conforme fórmula abaixo:

$\%$ de proteção $=($ Abs controle - Abs amostra $) / A b s$ controle

A determinação do teor de compostos fenólicos totais presentes na solução foi realizada por espectrofotometria na região do visível utilizando o método clássico de FolinCiocalteu e a absorbância das amostras foi medida a $750 \mathrm{~nm}$. O teor de fenólicos totais foi determinado por interpolação da absorbância das amostras contra uma curva de calibração construída com padrões de ácido gálico (0 a $20 \mu \mathrm{g} / \mathrm{mL}$ ) e expressos como mg de EAG (equivalentes de ácido gálico) por 100 gramas de amostra, conforme referenciado por $\mathrm{Melo}^{5}$.

\subsection{Análise sensorial}

Os testes sensoriais foram realizados no Laboratório de Análise Sensorial da Faculdade de Nutrição da UFF, em ambiente adequado, climatizado e arejado, sob luz natural. Foram recrutados 100 indivíduos de ambos os sexos, da própria universidade, aleatoriamente, com idade entre 18 e 58 anos.

Antes de iniciar a análise sensorial, os participantes foram solicitados a preencher um termo de consentimento livre e esclarecido a fim de garantir o caráter voluntariado da pesquisa. Em sequência, preencheram uma escala nominal a fim de se identificar o perfil de consumo.

Foram oferecidas quatro amostras de 20 gramas cada, para cada provador, de forma monádica. As amostras foram codificadas com tres dígitos, sempre acompanhadas de um copo com água à temperatura ambiente, e um biscoito água e sal para limpeza da boca e da língua antes de cada avaliação. Foi seguida uma ordem de apresentação aleatória ${ }^{6}$. 
Duas das amostras foram comerciais, escolhidas com base no nicho ocupado pelas formulações, sendo esse o apelo de saúde, adquiridas em lojas de produtos naturais, ambas sem glúten. Uma marca pronta para consumo e a outra, uma mistura para brownie sem glúten de outra marca, que foi preparada de acordo com as orientações do fabricante. Foi feito ainda um brownie de forma tradicional e o brownie desenvolvido com biomassa de fruta-pão verde.

As amostras ofertadas foram submetidas ao teste afetivo de aceitação, no qual foram avaliados os atributos sensoriais envolvidos: cor, aroma, sabor e textura, utilizando-se a escala hedônica estruturada de 9 pontos, cujas notas vão variar de 1 (desgostei extremamente) a 9 (gostei extremamente). Para o teste afetivo de aceitação utilizando a escala de atitude, as avaliações são desde "certamente compraria" (5) até "certamente não compraria" (1). Utilizando-se a metodologia (165/IV) recomendada pelo Instituto Adolfo Lutz - IAL ${ }^{1}$. O teste foi realizado com autorização previa do Comitê de Ética em Pesquisa da UFF, parecer número 1.024.216, aprovado em 10 de abril de 2015. O índice de aceitação das amostras foi calculado pela seguinte expressão matemática, utilizando o quesito da impressão global do produto $^{7}$ :

$$
\text { IA } \%=X^{*} 100 / \mathrm{N}
$$

Em que:

$\mathrm{X}=$ média de cada amostra

$\mathrm{N}$ = nota máxima de cada amostra dada pelos provadores.

Os resultados foram avaliados estatisticamente para obtenção de média e desvio padrão, e submetidos à análise de variância $(\mathrm{p}<0,05)$ ANOVA e ao teste de Tukey para comparação entre as médias utilizando o Programa ASSISTAT versão 7.7 beta.

\section{Resultados e Discussão}

\subsection{Composição centesimal}

A Tabela 1 mostra os resultados da composição centesimal do brownie de fruta-pão comparados aos resultados encontrados em estudo anterior para a biomassa de fruta-pão verde.

Tabela 1: Composição centesimal ( $\mathrm{g} / 100 \mathrm{~g})$ : biomassa de frutapão verde e brownie de biomassa de fruta-pão verde

\begin{tabular}{ccc}
\hline Fração & Biomassa & Brownie \\
\hline Umidade & $87,29 \pm 0,09^{\mathrm{b}}$ & $52,46 \pm 0,62^{\mathrm{c}}$ \\
Cinzas & $0,80 \pm 0,01^{\mathrm{b}}$ & $1,02 \pm 0,03^{\mathrm{c}}$ \\
Lipídeos & $0,39 \pm 0,03^{\mathrm{b}}$ & $2,42 \pm 0,36^{\mathrm{c}}$ \\
Proteínas & $1,19 \pm 0,13^{\mathrm{b}}$ & $6,27 \pm 0,08^{\mathrm{c}}$ \\
Carboidratos & $3,86 \pm 0,49^{\mathrm{b}}$ & $10,35 \pm 0,37^{\mathrm{c}}$ \\
Fibra & $12,66 \pm 0,55^{\mathrm{b}}$ & $12,07 \pm 0,29^{\mathrm{c}}$ \\
\hline
\end{tabular}

Fonte: Dados da pesquisa.

\subsection{Análise antioxidante}

Os resultados da análise de DPPH foram expressos em percentual de redução e EC50, que é a concentração de amostra capaz de remover $50 \%$ do radical livre DPPH, e foram comparados a resultados de estudos anteriores com valores para a fruta-pão in natura e biomassa de fruta-pão verde. Como pode ser observado na Tabela 2 , o extrato aquoso da fruta-pão apresentou $85 \%$ de redução do DPPH $\left(\mathrm{R}_{2} 0,97\right.$ / $\mathrm{EC}=0,87)$ após uma hora de contato. Já o extrato alcoólico apresentou $77 \%\left(\mathrm{R}_{2} 0,90\right)$ de redução. Demonstrando melhor extração no extrato aquoso, conforme o encontrado também por $\mathrm{Melo}^{8} \mathrm{em}$ seu estudo com polpas de frutas congeladas, no qual encontraram $89 \%$ de redução de DPPH em extrato aquoso para polpas de graviola e cajá, e $65 \%$ para polpas de maracujá e abacaxi. O extrato aquoso da biomassa apresentou $82 \%$ de redução do $\mathrm{DPPH}\left(\mathrm{R}_{2} 0,98 / \mathrm{EC}=1,18\right)$ e o do brownie $85 \%\left(\mathrm{R}_{2} 0,91 / \mathrm{EC}=0,70\right)$.

Tabela 2: Análise Antioxidante

\begin{tabular}{lcc}
\hline \multicolumn{1}{c}{ Amostra } & DPPH* & GAE * \\
\hline Fruta-pão verde & $85_{\mathrm{a}}$ & $615,98 \pm 12,44_{\mathrm{a}}$ \\
Biomassa de fruta-pão verde & $82_{\mathrm{b}}$ & $451,36 \pm 10,24_{\mathrm{b}}$ \\
Brownie de biomassa de fruta-pão verde & $85_{\mathrm{a}}$ & $654,76 \pm 4,10_{\mathrm{c}}$ \\
\hline Médias seguidas pela mesma letra na & mesma coluna não diferem \\
estatisticamente entre si (Teste de Tukey - 5\% probabilidade) \\
* Resultados expressos em percentual de redução \\
** Resultados expressos em mg de ácido gálico por $100 \mathrm{~g}$ de amostra. \\
GAE - "gallicacidequivalents"
\end{tabular}

Fonte: Dados da pesquisa.

Em relação aos compostos fenólicos, a fruta-pão apresentou $615,98 \pm 12,44 \mathrm{mg}$ de equivalente de ácido gálico (por $100 \mathrm{~g}$ de amostra), enquanto na biomassa foram encontrados $451,36 \pm 10,24 \mathrm{mg} / 100 \mathrm{~g}$ e no brownie 654,76 $\pm 4,10 \mathrm{mg} / 100 \mathrm{~g}$, como pode ser observado na Tabela 2 . Moura $^{9}$ encontrou na polpa da acerola $835,25 \mathrm{mg} / 100 \mathrm{~g}$ e no caju $449,63 \mathrm{mg} / 100 \mathrm{~g}$.

\subsection{Análise sensorial}

$O$ perfil de idade prevalente entre os entrevistados foi entre 20 e 29 anos. Como a pesquisa foi realizada na Faculdade de Nutrição, as mulheres estiveram presentes em maior quantidade que os homens. Diante disso, pode-se dizer que a maior parte dos participantes da pesquisa era mulheres adultas jovens.

Sobre a frequência mensal de consumo de brownies ou bolos de chocolate, verifica-se que a maioria das pessoas (91\%) que responderam à pesquisa consome esse tipo de produto ao menos uma vez por mês.

A Tabela 3 apresenta as notas atribuídas pelos provadores às quatro formulações de brownie. 
Tabela 3: Médias e desvio padrão das notas de cada atributo obtidas na análise sensorial

\begin{tabular}{ccccc}
\hline Atributos & Padrão & Biomassa & Pronto & Pó para Mistura \\
\hline Aparência & $7,95^{\mathrm{a}} \pm(1,12)$ & $7,62^{\mathrm{a}} \pm(0,92)$ & $6,71^{\mathrm{b}} \pm(1,82)$ & $4,95^{\mathrm{c}} \pm(1,93)$ \\
Aroma & $7,37^{\mathrm{a}} \pm(1,39)$ & $7,36^{\mathrm{a}} \pm(1,06)$ & $7,04^{\mathrm{a}} \pm(1,75)$ & $5,04^{\mathrm{b}} \pm(1,89)$ \\
Sabor & $7,83^{\mathrm{a}} \pm(1,33)$ & $6,93^{\mathrm{b}} \pm(1,31)$ & $6,79^{\mathrm{b}} \pm(1,84)$ & $5,26^{\mathrm{c}} \pm(2,24)$ \\
Textura & $8,05^{\mathrm{a}} \pm(1,31)$ & $5,20^{\mathrm{c}} \pm(2,39)$ & $6,51^{\mathrm{b}} \pm(1,84)$ & $5,29^{\mathrm{c}} \pm(2,28)$ \\
Impressão Global & $7,91^{\mathrm{a}} \pm(0,99)$ & $6,82^{\mathrm{b}} \pm(1,24)$ & $6,71^{\mathrm{b}} \pm(1,66)$ & $5,24^{\mathrm{c}} \pm(1,91)$ \\
Intenção de compra & $4,9^{\mathrm{a}} \pm(0,79)$ & $3,50^{\mathrm{b}} \pm(0,84)$ & $3,30^{\mathrm{b}} \pm(1,14)$ & $2,38^{\mathrm{c}} \pm(1,00)$ \\
\hline
\end{tabular}

Letras iguais na mesma linha representam resultados estatisticamente iguais, e letras diferentes representam diferença significativa pelo teste de Tukey $(\mathrm{p}<0,05)$.

Fonte: Dados da pesquisa.

Em relação ao atributo "aroma, a única amostra que se diferenciou das demais também foi a formulada com pó para mistura de brownie. Os comentários dos provadores foram: "cheiro de óleo"; "não tem cheiro de chocolate", entre outros.

Em relação ao sabor, a formulação mais bem aceita foi a padrão. A formulação com biomassa não apresentou diferença significativa em relação à pronta comercial. As principais observações dos provadores em relação ao sabor da formulação da biomassa foram: "menos doce que as outras"; "poderia ser mais doce"; "achei amargo". Isso se explica porque a formulação padrão é com açúcar refinado e chocolate em pó. Enquanto a formulação com biomassa é com açúcar demerara e cacau em pó. A falta do leite na formulação também altera a sensação de paladar adocicado. Os comentários para a formulação com pó e para o brownie pronto traziam observações em relação ao "gosto de química"; e do tipo "parece bolo pronto de mercado".

No atributo textura, pode-se observar que a formulação com biomassa não ficou muito bem colocada, sendo a preferida dos provadores a formulação tradicional. Em relação ao brownie pronto, os comentários foram "muito esfarelento"; "muito enfarinhado"; "parece farofa", entre outros. Já para a formulação com biomassa, o que mais foi observado pelos provadores foi a textura "amolecida"; "mole"; "melequenta"; "úmido demais", entre outras expressões. O que pode não ser um grande problema. Tanto que alguns provadores que atribuíram maior nota para a textura, justamente se agradaram com a textura macia. Mas quando comparada com brownies, de fato, até por não conter nenhum tipo de farinha em sua formulação, ele se apresenta bem mais úmido.

Em relação ao atributo impressão global, a formulação padrão foi melhor aceita, seguida pela formulação com biomassa que não diferiu da pronta. E por último, o pó para mistura, como pode ser observado na Tabela 3.

Foi calculado, ainda, o IA (Índice de Aceitabilidade) de cada atributo.

Ao observar o IA da Impressão Global, conclui-se que a amostra que teve melhor aceitação foi a de formulação tradicional, seguida da amostra do presente estudo, formulada com biomassa de fruta-pão verde, e depois a amostra de soja que é vendida pronta para consumo. E por último, a amostra correspondente ao pó para mistura de brownie de soja. Os resultados podem ser melhor observados na Figura 1.

Figura 1: IA (Índice de Aceitabilidade) \% dos atributos

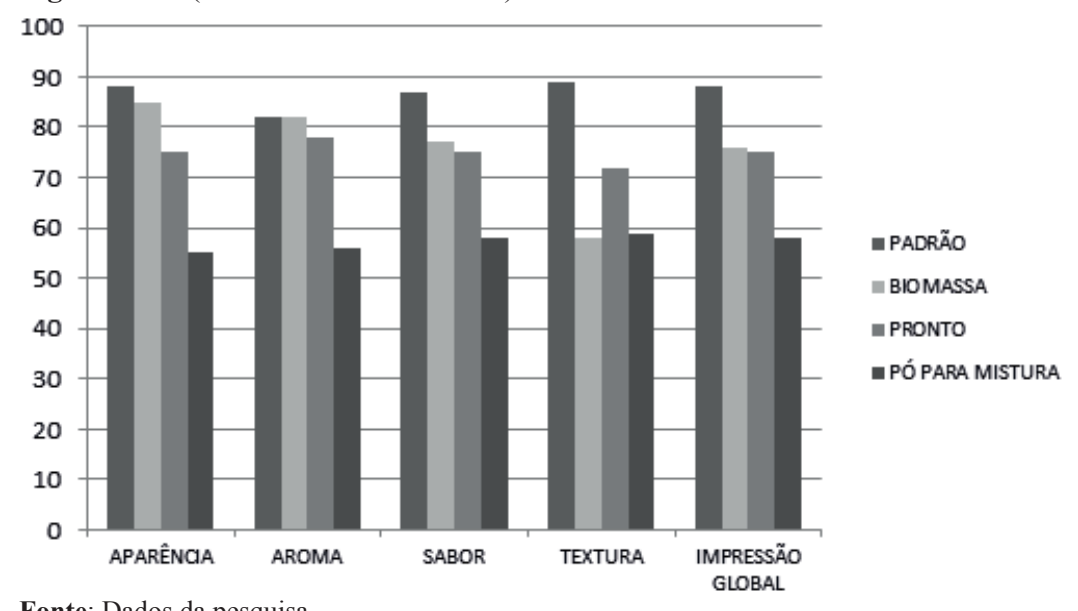

Fonte: Dados da pesquisa.

De acordo com Finger ${ }^{7}$, para uma boa repercussão o índice de aceitação deve ser superior a $70 \%$. Desse modo, podemos afirmar que em relação à impressão global, apenas a amostra "Pó para Mistura" não teve boa aceitação. 
Também foi analisada a atitude de compra dos provadores com a escala de 5 pontos, sendo: "certamente não compraria"; provavelmente não compraria"; "talvez comprasse/talvez não comprasse"; "provavelmente compraria" e "certamente compraria". A amostra que apresentou melhor nota média foi a de formulação padrão, como o esperado (Figura 1).

Na Tabela 4, encontra-se um comparativo dos resultados da composição centesimal do brownie de biomassa de frutapão verde com um brownie comercial sem glúten e sem lactose.

Tabela 4:Composição centesimal (g/100g): brownie de biomassa de fruta-pão verde e brownie comercial pronto sem glúten

\begin{tabular}{ccc}
\hline Fração & Biomassa & Comercial \\
\hline Lipídeos & 2,4 & 18,1 \\
Proteínas & 6,3 & 5,3 \\
Carboidratos & 10,4 & 51,6 \\
Fibra & 12,07 & 1,6 \\
Caloria & 88 & 392 \\
\hline
\end{tabular}

Fonte: Dados da pesquisa.

Os resultados demonstram que a fruta-pão apresenta excelente capacidade antioxidante, até maior que a de algumas frutas encontradas na literatura. Estudos têm mostrado que os compostos fenólicos geralmente diminuem em frutos climatérios, como tomates, bananas, mangas e goiabas durante o amadurecimento ${ }^{10}$, o que também pode ter contribuído para a alta capacidade antioxidante apresentada, já que o presente estudo se trata do fruto ainda verde. Observa-se que a capacidade antioxidante diminuiu, mas persistiu alta na biomassa desenvolvida, sugerindo que ela pode ser utilizada com perdas não significativas do valor nutricional e funcional.

Interessante notar ainda que a capacidade antioxidante volta a crescer no brownie desenvolvido com a biomassa de fruta-pão verde. O que pode ser atribuído ao cacau acrescentado à receita, que possui reconhecido valor antioxidante, ou ainda ao fato que $\mathrm{Melo}^{8}$ estudou sobre o efeito do tratamento térmico na capacidade antioxidante em hortaliças. No qual citou que durante o tratamento térmico podem ocorrer vários eventos os quais justificam a alteração da capacidade antioxidante, podendo não alterar, aumentar ou reduzir a ação antioxidante do alimento. Na situação em que se observa aumento da ação antioxidante no alimento, o tratamento térmico propicia a oxidação parcial do composto bioativo que exibe maior habilidade em doar o átomo de hidrogênio ao radical a partir do grupo hidroxil e/ou a estrutura aromática do polifenol apresenta maior capacidade em suportar o deslocamento do elétron desemparelhado em volta do anel. Além disso, o tratamento térmico pode favorecer a formação de novos compostos, como os produtos da reação de Maillard (redutonas), que têm ação antioxidante ${ }^{11}$. Interessante ressaltar que a fruta-pão verde apresentou um valor intermediário entre as frutas já reconhecidas como fontes de antioxidantes, como a acerola e o caju.

Em relação ao perfil dos provadores que participaram da análise sensorial, como é um produto que abrange extensa faixa etária, seria mais interessante se houvesse equilíbrio de quantidade de pessoas em cada faixa etária. Porém, este fator não compromete o desenvolvimento do produto, segundo Borges $^{12}$, embora não constitua alimento básico como o pão, o brownie é aceito e consumido por pessoas de qualquer idade.

Conforme a Abima (Associação Brasileira das Indústrias de Massas Alimentícia e Pão \& Bolos Industrializados), devido ao aumento do poder aquisitivo e da ascensão das classes D e E, o brasileiro está com paladar sofisticado. Um dos setores que pode refletir bem essa mudança de comportamento de consumo é o de bolo pronto. De acordo com um estudo feito pela Kantar Worldpanel ${ }^{13}$, a categoria estava presente em $41 \%$ dos lares brasileiros em 2011, mas subiu para $45 \%$ em 2012, o que significa que mais de 2 milhões de famílias passaram a comer bolo pronto em um ano. Este foi o setor que mais cresceu entre os derivados de trigo analisados pela consultoria. Isso explica a frequência com que os provadores consomem brownie ou bolo de chocolate.

Como pode ser observado na Tabela 3 no atributo "aparência", o brownie de biomassa não apresentou diferença significativa em relação à formulação padrão. Ambos obtiveram boas notas. O brownie pronto não pontuou tão bem, mas ficou acima da média, enquanto o pó para mistura ficou abaixo da média. Os comentários dos provadores para este último foram: "não parece brownie"; "cor feia", entre outros.

A amostra formulada com biomassa não apresentou diferença significativa para a amostra comercial pronta (Tabela 3). Isso representa um bom resultado, já que o brownie comercial pronto é de uma marca sólida no mercado, que comercializa produtos sem glúten e lactose. Sendo ainda que a formulação com biomassa tem um apelo funcional infinitamente maior, pois se trata de uma formulação sem leite, sem nenhum tipo de farinha, sem nenhum tipo de gordura e com açúcar demerara orgânico. A marca pronta do mercado possui vasta lista de ingredientes processados: açúcar; mix sem glúten (farinha de arroz integral, amido de milho, fécula de mandioca, farinha integral de soja); óleo vegetal; castanha de caju; ovos; cacau em pó; além de conservantes e aromatizantes. Sem contar que o brownie de biomassa de fruta-pão verde tem ainda antioxidantes naturalmente encontrados nas frutas.

\section{Conclusão}

O presente estudo constatou que mesmo com o processamento e submissão à alta temperatura para a produção de biomassa e posterior produção de brownie de biomassa de fruta-pão verde, não houve perda significativa de nutrientes. A presente pesquisa denotou que há viabilidade para produção e comercialização dos brownies devido ao baixo custo dos seus ingredientes, simplicidade de preparo e manutenção 
de propriedades funcionais. A aceitação sensorial aferida foi satisfatória, já que o Índice de Aceitabilidade (IA) para a impressão global foi superior a 70\%. Como a fruta-pão é mais abundante justamente em regiões menos favorecidas economicamente, e seu consumo ainda é pouco difundido, conclui-se que o incentivo no aproveitamento dessa fruta em outros territórios nacionais traria maior renda para pequenos produtores rurais e maior aproveitamento da produção anual, diminuindo o desperdício da fruta e contribuindo dessa forma com a saúde pública, visto que se trata de um produto com apelo funcional, e com a economia do país, por meio de nova geração de renda.

\section{Referências}

1. Petitgastrô. História do brownie. 2012. [acesso em 18 abr 2015]. Disponível em http://www.petitgastro.com. br/2012/01/historia-do-brownie/.

2. São Paulo. Normas analíticas do Instituto Adolfo Lutz. Métodos físicos e químicos para análise de alimentos. São Paulo: IAL; 2008.

3. Van Soest PJ. The use of detergents in the analysis of fibrous feeds: II. a rapid method for the determination of fiber and lignin. Offic Agric Chem 1963;46:829.

4. Prior RL,Wu X, Schaich K. Standardized methods for the determination of antioxidant capacity and phenolics in foods and dietary supplements. J Agric Food Chem 2005;53:4290302.
5. Melo EA. Capacidade antioxidante de hortaliças usualmente consumidas. Ciênc Tecnol Aliment 2006;26(3):639-44.

6. Martínez-Cervera S. Rheological, textural and sensorial properties of low-sucrose muffins reformulated with sucralose/polydextrose. LWT Food Sci Technol 2012;45:21320.

7. Finger CL, Scheidt DT, Deina LE. Desenvolvimento e análise sensorial de petit suisse de maracujá e mexerica. In: Anais do $2^{\circ}$ Encontro de Divulgação Científica e Tecnológica. Universidade Tecnológica Federal do Paraná, Paraná, 2010.

8. Melo EA. Total phenolic contents and antioxidant capacity of the frozen fruit pulps. Alim Nut 2008(19):67-72.

9. Moura SM. Estabilidade da acerola em pó oriunda de cultivo orgânico. 2010. Dissertação. [Mestrado em Ciência e Tecnologia de Alimentos] Universidade Federal do Ceará; 2010.

10. Georgé S. Changes in the contents of carotenoids, phenolic compounds and vitamin $\mathrm{C}$ during technical processing and lyophilisation of red and yellow tomatoes. Food Chem 2011;124(4):1603-11.

11. Nicoli MC, Anese M, Parpinel M. Influence of processing on the antioxidant properties of fruits and vegetables. Food Sci Technol 1999(10):94-100.

12. Borges JTDS. Utilização de farinha mista de aveia e trigo na elaboração de bolos. Boletim Ceppa 2006;1(14):145-62.

13. ABIMA. Associação Brasileira das Indústrias de Massas Alimentícias e Pãos Bolos Industrializados. ABIMA. 2013. [acesso em 9 nov 2015]. Disponível em http://www.abima. com.br/noticias eabima.php?id=765. 